\title{
Acid Activation of Natural Zeolite with High Content of Iron Oxides in Creation of Selective Sorbents and Catalysts
}

\author{
Kairat Kadirbekov ${ }^{1,2,}{ }^{*}$, Dauren Zhambakin ${ }^{1}$, Almaz Kadirbekov $^{1,2}$, and Kylysh Imanbekov ${ }^{2}$ \\ ${ }^{1}$ LLP "Kazatomprom-Sorbent” Almaty, Kazakhstan \\ 2 JSC “A.B. Bekturov Institute of Chemical Sciences”, Almaty, Kazakhstan
}

\begin{abstract}
The paper studies the influence of the nature of modifying acids (mineral, organic and heteropolyacids), and their combination on the composition and structure of the iron oxide rich clinoptilolit from Shankanay field in Kazakhstan for creation of selective catalysts in hydracarbon processing and sorbents for extracting ions of lanthanide and actinide elements. It is shown that sequential processing of natural zeolite in optimal conditions, by hydrochloric and sulfosalicylic acids lead to intensive decationization and dealumination, as well as maximum removal of iron ions from the zeolite framework without destroying it. It is found that the combination of activated clinoptilolite with hydrochloric acid and phosphotungstic heteropolyacid contributes to obtain catalyst system with high surface area and acidity.
\end{abstract}

\section{Introduction}

Zeolites are versatile catalyst systems [1-3]. They are processed using the most diverse hydrocarbon feedstock and produced to a wide range of commercially important products - components of fuels and synthetic oils, monomers and intermediates of petrochemical synthesis and others. In addition, modern sorption technology based on zeolite obtained qualitatively new sorbents with increased capacity and high selectivity of action. In [412] shows the prospects of their application in many catalytic and sorption processes.

In the last 10 years, authors are performing intensive research on the construction of catalytic systems and the creation of sorbents for the extraction of metals by modifying the natural zeolite Shankanay field (Kazakhstan) [13-15].

Shankanay natural zeolites have a high content of iron oxides, along with oxides of alkali and alkaline earth metals in their composition. It is generally known that for the selective removal of ferric ions which catalyze the carburization process in the processing of hydrocarbons using zeolite chelating treatment is carried out with these organic acids. It is also known that the need to strengthen the forces of acid centers, which is cracking reaction, it is recommended to run the process with the use of heteropolyacids or superacids.

At the same time, the effect of sequential treatment of natural zeolite with mineral then organic acids or mineral acid then heteropolyacids on activity, selectivity and catalyst stability of studied systems in specific chemical reaction (cracking hydrocarbons) has been studied insufficiently. In addition, the development of new catalysts for petrochemical processes or special sorbents for the extraction of rare elements require a large amount of systematic research work aimed at the establishment of physical and chemical laws of formation of complex catalytic systems according to the properties of their individual components, phase composition, structure, and so on. The solution of these important issues is dedicated to the proposed work.

\section{Experimental Part}

As the object of research natural zeolites of Shankanay field (Kazakhstan) was taken, in which the major rockforming mineral is acid- and heat-resistant clinoptilolite.

Sorbents and catalysts based on natural zeolite of Shankanay field were synthesized by modification with mineral acids, organic acids, and heteropolyacids (HPA).

Handing out of zeolite by mineral acids was performed in order to remove the cations of various metals from the surface (primarily alkali and alkaline earth). Thus, one-, two- and three-time modification of natural zeolite by $1.75 \mathrm{~N}$ hydrochloric acid following cracking catalysts were prepared: HKl-1, HKl-2 and HKl-3.

Treatment of zeolite by organic acids was carried out for the selective removal of ferric ions which catalyze the process of carbonization. To remove $\mathrm{Fe}^{3+}$ ions chelating agents were used: citric acid and sulfosalicylic acid (10 and $20 \%$ solutions), ethylenediaminetetraacetic acid and its disodium salt EDTA (Trilon B, 10\% aqueous solution). All of them form with iron ions stable watersoluble complexonates. Treatment by chelating agents were performed on natural $(\mathrm{Kl})$ and pre decationized by hydrochloric acid (HKl-1) samples.

Treatment by HPA was carried out for enhancing the force of acidic centers at which the cracking reaction occurs. For that reason, new cracking catalysts prepared

\footnotetext{
Corresponding author: kkairati@mail.ru
} 
by modifying the decationized natural zeolite with heteropolyacids of molybdenum and tungsten series: $\mathrm{PMo}_{12}-\mathrm{HPA} / \mathrm{HK}$ land $\mathrm{PW}_{12}-\mathrm{HPA} / \mathrm{HK}$. HPA was applied on the surface of decationized natural zeolite (HKl) in an amount of from 1 to $10 \%$ by the well-known impregnation technique.

Modification of natural zeolite samples (Kl) was performed by the method of Kerr in a Soxhlet apparatus. When heated, the cartridge with an acid placed in an extractor, while aqueous suspension of the zeolite placed in a water bath heated flask. And the "direct" method performed by placing the cartridge with the acid directly into a flask with acidified zeolite suspension. All samples were dried in an oven and calcined at $500^{\circ} \mathrm{C}$ for 4 hours in a muffle furnace.

An acid modification was conducted for 1.6-2 mm fraction of the zeolite (the ratio S:L of 1:10 wt.) at the processing temperature $94-98^{\circ} \mathrm{C}$ during 10 hours. After a predetermined time, the samples were washed thoroughly from residual acid and dried to air-dry state.

Oxide and elemental composition of samples of Shankanay field was identified by emission spectral analysis on diffractometer DFS-13.

X-ray analysis of natural zeolite and its' modified forms was performed on a D8 Advance (Bruker), $\alpha-\mathrm{Cu}$, tube voltage $40 \mathrm{kV}$, current $40 \mathrm{~mA}$. Data processing and calculation of the diffraction patterns, calculation of interplanar distances were performed using the software EVA. Deciphering of samples and phases search were carried out under the Program Search / Match with Database of powder diffractometric data PDF-2 Rel. 2012 (ICDD).

IR study of samples was conducted by the spectrometer NICCOLET-2700 in the frequency range $400-4400 \mathrm{~cm}^{-1}$. The catalyst was formed into a tablet "thickness" of $60-100 \mathrm{mg} / \mathrm{cm}^{2}$. Adsorption of test gases was carried out at different temperatures, vacuuming 10 5 Torr.

\section{Results and Discussion}

\subsection{Modifying the natural zeolite with an inorganic acid}

In order to produce modified forms of Shankanay zeolites applied acid activation technique was applied.

Acid resistance of natural zeolites is essential for their technological applications, as well as the study of conditions for the preservation of different samples crystallinity of acid activated clinoptilolite will create a basis for the preparation of intermediates in the degree of dealumination and decationization of samples that have acidic properties, which play a major role in the catalytic cracking, and sorbents with high capacity volume.

It was determined that by treating $1.5 \mathrm{~N} ; 1.75 \mathrm{~N}$ (optimum concentration) and $2.0 \mathrm{~N}$ hydrochloric acid for 6 hours at a temperature of $96-98^{\circ} \mathrm{C}$ clinoptilolite was subjected to dealumination and decationization without appreciable destruction of the crystal lattice. Thus, acid treatment results in changes in the chemical composition of samples of natural zeolite in the process of modification: with increasing concentration of the activating acid simultaneously reduced oxides content of divalent metals and iron oxide in HKl samples.

However, on the degree of dealumination and decationization, apart from acid concentration, affect temperature, the amount of the acid solution, the duration and frequency of treatment. Consequently, on the basis of natural zeolite of Shankanay field following modified forms were obtained: treating the clinoptilolite by $1.75 \mathrm{~N}$ hydrochloric acid (designated as sample HKl1), twice processing fresh portions of the same concentration of acid (HKl-2) and three-time processing of fresh portions of $10 \%$ hydrochloric acid (HKl-3).

The composition of the prepared modified forms of natural zeolite samples, as determined by emission spectral analysis is shown in Table 1.

Table 1. The oxide composition of samples modified by mineral acids.

\begin{tabular}{|c|c|c|c|c|}
\hline Oxide & \multicolumn{1}{l|}{ Kl } & HKl-1 & HKl-2 & HKl-3 \\
\hline $\mathrm{Al}_{2} \mathrm{O}_{3}$ & 8.5 & 5.7 & 4.5 & 2.4 \\
\hline $\mathrm{SiO}_{2}$ & 65.0 & 80.0 & 78.0 & 89.0 \\
\hline $\mathrm{Fe}_{2} \mathrm{O}_{3}$ & 10.2 & 2.7 & 3.5 & 1.2 \\
\hline $\mathrm{CaO}$ & 3.5 & 0.7 & 0.2 & 0.1 \\
\hline $\mathrm{MgO}$ & 2.5 & 1.1 & 0.3 & 0.5 \\
\hline $\mathrm{Na}_{2} \mathrm{O}$ & 2.1 & 1.8 & 0.4 & 1.2 \\
\hline $\mathrm{K}_{2} \mathrm{O}$ & 2.3 & 1.8 & 0.1 & 1.6 \\
\hline $\mathrm{SiO}_{2} / \mathrm{Al}_{2} \mathrm{O}_{3}$ & 13.1 & 23.8 & 29.5 & 63.0 \\
\hline
\end{tabular}

When treating zeolite by hydrochloric acid, content of mono- and divalent metal oxide and iron oxide, carbon ions which catalyze carburization, reduces from $10.2 \mathrm{wt} \%$. in natural to $2.7 \mathrm{wt} \%$. in acid activated sample. The amount of iron oxide, as compared with the quantity of the sample HK1-1 (2.7\%), doubly treated zeolite sample with $1.75 \mathrm{~N}$ hydrochloric acid is $3.5 \%$, and three times treated with $10 \%$ hydrochloric acid solution is reduced to $1.2 \%$. The amount of alumina varies from 8.5 to $2.4 \%$, i.e. reduced by $72 \%$, whereas the $\mathrm{SiO}_{2}$ content in samples of zeolite increases from 65.0 to $89.0 \%$. This leads to increase of the value of silica modulus (molar ratio of $\mathrm{SiO}_{2} / \mathrm{Al}_{2} \mathrm{O}_{3}$ ), with the first 13.5 (HKl-1) to 23,75 (HKl-2), then rapidly to 63 (HKl3 ). The observed increase of silica modulus from 13.5 to 23.75 , by which indirectly judge the acidic properties of the samples indicates the occurrence of acid sites. Under the influence of acids with low concentration there is exchange of zeolite cations into protons to form hydrogen form of zeolite (Broensted acid site). With the increase of acid concentration is obtained aluminum form by switching from aluminum tetrahedral coordination in the exchange position of the threecoordinated (Lewis Center).

It should be noted that excessively removing aluminum oxide from clinoptilolit (more than 50\%) reduces the strength of the crystal structure of clinoptilolite. Indeed, by increasing the multiplicity of hydrochloric acid treatment of the clinoptilolit, dealumination and the formation of the amorphous phase is observed. 
As an example, in Figure 1, HKl-1 is sample of natural zeolite treated by $1.75 \mathrm{~N}$ hydrochloric acid is presented.

X-ray picture of the zeolite sample (Fig.1) shows that the main minerals which form a solid framework of the zeolite is clinoptilolite with formula $\mathrm{Na}_{8}\left(\mathrm{Al}_{6} \mathrm{Si}_{30} \mathrm{O}_{72}\right)\left(\mathrm{H}_{2} \mathrm{O}\right)_{9}$. Usual crystal-clinoptilolite formula: $(\mathrm{Na}, \mathrm{K}) 6\left[\mathrm{Al}_{6} \mathrm{Si}_{30} \mathrm{O}_{72}\right] * 24 \mathrm{H}_{2} 0$. Together with clinoptilolite accompany minerals: analcime $\mathrm{Na}_{16.24} \mathrm{Al}_{16.00} \mathrm{Si}_{32.00} \mathrm{O}_{96} \quad\left(\mathrm{H}_{2} \mathrm{O}\right)_{16} \quad$ (chemical formula $\left.\mathrm{Na}\left[\mathrm{AlSi}_{2} \mathrm{O}_{6}\right] \cdot \mathrm{H}_{2} \mathrm{O}\right)$, quartz $\left(\mathrm{SiO}_{2}\right)$ and feldspars. Feldspars are presented in the form of solid solutions of the ternary system isomorphous series $\mathrm{K}\left[\mathrm{AlSi}_{3} \mathrm{O}_{8}\right]-$ $\mathrm{Na}\left[\mathrm{AlSi}_{3} \mathrm{O}_{8}\right]-\mathrm{Ca}\left[\mathrm{Al}_{2} \mathrm{Si}_{2} \mathrm{O}_{8}\right]$ (or K-Na-, Ca-Nafeldspars), in particular in the form of albite $\mathrm{Na}\left[\mathrm{AlSi}_{3} \mathrm{O}_{8}\right]$. From the remaining minerals it can be identified widespread iron minerals - hematite $\mathrm{Fe}_{2} \mathrm{O}_{3}$ and siderite $\mathrm{FeCO}_{3}$.

Comparison of X-ray data of initial and acid activated samples pointed on changes in the structure of the mineral acid in the process of acid activation.

It was revealed that after treatment by $1.75 \mathrm{~N}$ acid, mineral structure remained unchanged, but compared with the diffraction pattern of the initial sample of natural zeolite, there was a decrease of the intensity of one of the main reflections characteristic of the mineral $(8.92 \AA)$, as well as an increase in the reflection characteristic amorphous phase (3,3 $\AA$ ).

When $\mathrm{HKl}$ sample was treated with $1.75 \mathrm{~N} \mathrm{HCl}$ acid there was dissolution of quartz, feldspar, and their value reduced by $20-25 \%$. Furthermore, in the HKl sample, there is a decrease of phases with iron oxide minerals: hematite content decreases, siderite dissolved by the mineral acid.

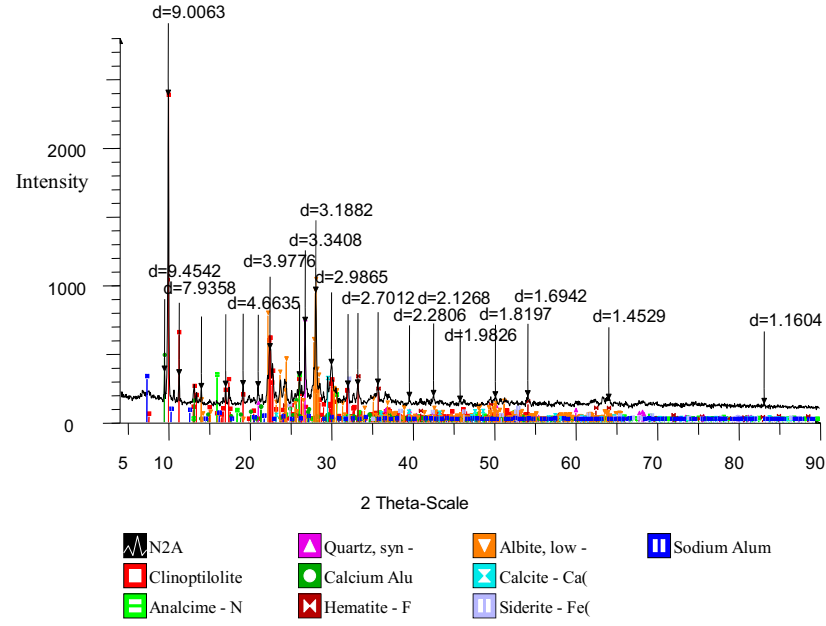

Fig. 1. X-ray of HKl-1 sample - obtained by treating natural zeolite of Shanhanay field by $1.75 \mathrm{~N}$ hydrochloric acid.

As a result of acid activation there is an increase in the content of rock-forming minerals - clinoptilolite. Clinoptilolite phase in the sample HKl under the influence of $1.75 \mathrm{~N} \mathrm{HCl}$ compared with $\mathrm{Kl}$ source is increased by $20 \%$.

Analysis of the IR spectra showed that natural Shankanay clinoptilolite sample is characterized by the following absorption bands: 465, 615, 780, 1060, 1635, $3460 \mathrm{~cm}^{-1}$ (Fig.2, spectrum 1). These characteristic absorption bands are present in the spectra of all the samples of zeolite (Fig.2, spectra 2 and 3). Here, spectrum bands $465,615,780 \mathrm{~cm}^{-1}$ result from internal and external vibrations alumo-silicate zeolite framework $\mathrm{Si}(\mathrm{Al})$. Most high intensity of the absorption band is observed in the frequency range $1060-1080 \mathrm{~cm}^{-1}$, which correspond to the stretching vibrations of the Al-O-Si and Si-O-Si frame bonds.

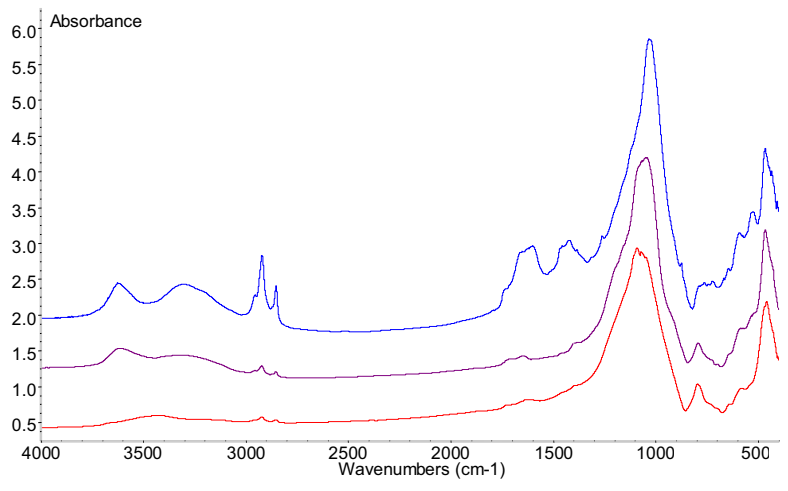

Fig. 2. IR spectra of the samples obtained by modifying the clinoptilolite 1 - Kl; 2 - HKl -1 ; 3 - HKl -1/Sal-1(1.75N $\mathrm{HCl}+10 \%$ HSal).

It is noticed that the spectra of the sample $\mathrm{Kl}$ treated by $1.75 \mathrm{~N} \mathrm{HCl}$, the relative intensities of the absorption bands are associated with the crystalline phases and within the tetrahedral vibrations do not undergo any significant changes. These facts suggest retaining the original crystal structure of the mineral. At the same time, it is observed the appearance of a new absorption band in the $796 \mathrm{~cm}^{-1}$, also there is an increase in intensity are seen as a shoulder at $980 \mathrm{~cm}^{-1}$ band and an offset from 1095 to $1065 \mathrm{~cm}^{-1}$.

The appearance of a new absorption band at $796 \mathrm{~cm}^{-1}$ corresponding to the stretching vibrations of $\mathrm{Si}-\mathrm{O}$ linkages indicates the formation of free silica and exit of aluminum to an exchange position. Absorption band at $796 \mathrm{~cm}^{-1}$ one can determine to the formation of new bonds $\mathrm{Si}-\mathrm{O}-\mathrm{Si}$ at break of Al-O-Si- bonds. Observed shifting of band from $1065 \mathrm{~cm}^{-1}$ to $1095 \mathrm{~cm}^{-1}$ due to the formation of new Si-O-Si-bonds due to release of $\mathrm{Al}$ from tetracoordinated position to an exchange position.

The above qualitative and quantitative X-ray and IR data indicate that when acidizing $\mathrm{Kl}$ undergoes deep dealumination without noticeable destruction of the structure of the mineral.

Thus, when used for treatment of relatively dilute acid clinoptilolite decationization occurs to form the hydrogen form, and simultaneously dealumination accompanied by partial amorphization of zeolite occurs.

Modification of the zeolite samples with an inorganic acid under optimal conditions enhance their catalytic properties (in the silicate modulus) sorption capacity and, but at the same time is not able to remove iron oxides from the zeolite.

Conclusin that in acid treatment clinoptilolit undergoes deep dealumination without appreciable destruction of the mineral structure is confirmed by X-ray obtained on the unit D8 Advance (Bruker), as well as IR data. 


\subsection{Modifying the natural zeolite with an organic acid}

During activation of natural zeolite of Shankanay field by mineral acid there is easily removing cations of alkali and alkaline earth metals, and partly iron cations. However, the residual amount of iron in the composition of the zeolite, even under optimum conditions of acid activation, negatively effects on the catalyst (sorbent) performance, in particular on the hydrocarbons cracking process by catalyzing carbonization process from hydrocarbons.

To remove $\mathrm{Fe}^{3+}$ ions natural samples were treated by chelating agents: ethylenediaminetetraacetic acid (H4EDTA, 10 and 25\% solutions), sulfosalicylic acid (HSal, 10 and 25\% solutions), citric acid (H-Lim, 10 and $25 \%$ solution), and disodium salt of H4-EDTA (Na2H2Y or Trilon B, $10 \%$ solution). All of them forms stable water-soluble complexes with iron ions, in particular the first choice for sulfosalicylic acid based on the ability of specific aromatic oxy acids, to form internal chelate compound.

Composition of samples obtained by direct modification of internal natural zeolite by some organic acids is shown in Table 2 .

Table 2. The oxide composition of the samples modified with organic acids.

\begin{tabular}{|c|c|c|c|c|}
\hline Oxide & $\begin{array}{l}\text { Kl } \\
\text { (natural } \\
\text { ) }\end{array}$ & $\begin{array}{l}\text { Kl- } \\
\mathbf{H}_{4} \text { EDTA }\end{array}$ & $\begin{array}{l}\text { Kl - } \\
\text { HSal }\end{array}$ & $\begin{array}{l}\text { Kl - } \\
\text { HLim }\end{array}$ \\
\hline $\mathrm{Al}_{2} \mathrm{O}_{3}$ & 12.1 & 12.8 & 9.6 & 14.1 \\
\hline $\mathrm{SiO}_{2}$ & 68.0 & 74.0 & 74.0 & 71.0 \\
\hline $\mathrm{Fe}_{2} \mathrm{O}_{3}$ & 9.5 & 4.0 & 4.4 & 4.9 \\
\hline $\mathrm{CaO}$ & 3.5 & 1.0 & 0.1 & 0.2 \\
\hline $\mathrm{MgO}$ & 2.5 & 1.0 & - & - \\
\hline $\mathrm{K}_{2} \mathrm{O}$ & 2.3 & 1.5 & - & - \\
\hline $\mathrm{Na}_{2} \mathrm{O}$ & 2.1 & 1.0 & 2.8 & 2.0 \\
\hline $\mathrm{SiO}_{2} / \mathrm{Al}_{2} \mathrm{O}_{3}$ & 9.6 & 9.9 & 13.1 & 8.6 \\
\hline
\end{tabular}

When treating clinoptilolite with organic acids amount of alumina in its composition varies slightly, zeolite dealumination process is not compared with decationization of zeolite. This is evidenced by similar values of silicate source module $\left(\mathrm{SiO}_{2} / \mathrm{Al}_{2} \mathrm{O}_{3}=9.6\right)$ and modified $\left(\mathrm{SiO}_{2} / \mathrm{Al}_{2} \mathrm{O}_{3}=9.9\right.$ - 13.1) zeolite samples. At the same time, the nature of the organic acid affects the silicate modulus of samples in different ways. Ethylenediaminetetraacetic acid regardless of the method does not change the value of the activation module silicate $\left(\mathrm{SiO}_{2} / \mathrm{Al}_{2} \mathrm{O}_{3}=9.6\right.$ and 9.9). Citric acid lowers the silica modulus clinoptilolite to 8.6 , while sulfosalicylic acid increases it to 13.1 .

With regard to the composition of oxides in the clinoptilolite, their relative contents in the dissolution under the action of organic acids are reduced. The amount of alkali metal oxides in the composition of the natural zeolite is reduced slightly at the same time oxides of alkaline-earth metals are removed almost completely. Content of iron oxide also decreases, and its residual amount is $4.0-5.0 \%$.

It was revealed the effect of organic acids on the chemical structure and acidic properties of natural zeolite as compared with an inorganic acid is negligible. After organic acid modification natural zeolite by mainly decationization than dealumination processes occur. By modification of natural zeolite directly with organic acid the amount of undesired in catalytic processes iron oxide reduce only twice. Apparently, the organic acid do not reach iron ions, which are disposed within the crystal structure of clinoptilolite, but only interacts with the surface ions.

Among the organic acids used for decationization and dealumination as well as removal of iron ions from the clinoptilolite, using sulfosalicylic acid is more efficient.

\subsection{Stepped modification of natural zeolite first with mineral and then by organic acids}

Direct application of iron-chelate forming organic acids for modification of natural reduces the amount of iron oxide in the composition of the zeolite, but not changing the meaning of silica modulus of clinoptilolite.

In consequence, in order to obtain from Shankanay clinoptilolite catalysts with high acidity surface and low iron oxide content in the composition, natural zeolite is subjected to a stepwise modification of the mineral and the organic acids.

As the inorganic acid is taken $1.75 \mathrm{~N}$ hydrochloric acid, as organic - sulfosalicylic acid (10 and 20\% solutions) and ethylenediaminetetraacetic acid (10\% solution).

Changes in the composition of the samples obtained by the two-stage modification of clinoptilolite are shown in Table 3.

Table 3. The oxide composition of the natural zeolite sample modified with two-stepped method.

\begin{tabular}{|c|c|c|c|c|}
\hline Oxide & $\begin{array}{c}\mathrm{Kl} \\
\text { (natural) }\end{array}$ & $\begin{array}{c}\mathrm{HKl-1/} \\
\mathrm{Sal}-1 \\
(1.75 \mathrm{~N} \\
\mathrm{HCl} \\
10 \% \\
\mathrm{HSal})\end{array}$ & $\begin{array}{c}\mathrm{HKl}-1 / \\
\mathrm{HSal}-2 \\
(1.75 \mathrm{~N} \\
\mathrm{HCl} \\
20 \% \\
\mathrm{HSal})\end{array}$ & $\begin{array}{c}\text { HKl-1/ } \\
\mathrm{H}_{4} \text { EDTA } \\
1.75 \mathrm{NCl} \\
10 \% \\
\left.\mathrm{H}_{4} \text { EDTA }\right)\end{array}$ \\
\hline $\mathrm{Al}_{2} \mathrm{O}_{3}$ & 12.1 & 7.2 & 7.8 & 10.7 \\
\hline $\mathrm{SiO}_{2}$ & 68.0 & 82.0 & 77.0 & 78.3 \\
\hline $\mathrm{Fe}_{2} \mathrm{O}_{3}$ & 9.5 & 1.2 & 4.0 & 3.5 \\
\hline $\mathrm{CaO}$ & 3.5 & 0.2 & 0.3 & 0.5 \\
\hline $\mathrm{MgO}$ & 2.5 & 0.8 & 1.0 & 1.0 \\
\hline $\mathrm{K}_{2} \mathrm{O}$ & 2.3 & 1.5 & 2.0 & 2.0 \\
\hline $\mathrm{Na}_{2} \mathrm{O}$ & 2.1 & - & 1.5 & 1.0 \\
\hline $\mathrm{SiO}_{2} /$ & 9.6 & 19.4 & 16.8 & 12.6 \\
$\mathrm{Al}_{2} \mathrm{O}_{3}$ & & & & \\
\hline
\end{tabular}

When $\mathrm{H}_{4}$ EDTA is used in the second stage of acid activation, despite the significant decationization of zeolite, content of iron oxide is reduced to only $3.5 \%$, while the value of the silica modulus of the sample remains low (12.6).

Application of another acid, $10 \%$ solution of sulfosalicylic acid, in the second step of modification dramatically reduces the iron oxide content of the zeolite 
in the sample to $1.2 \%$. The extent of dealumination of the zeolite is also at a high level $\left(\mathrm{SiO}_{2} / \mathrm{Al}_{2} \mathrm{O}_{3}=19.4\right)$.

It should be noted that increasing the concentration of sulfosalicylic acid twice, from 10 to $20 \%$ in the second step did not improve the performance of the catalysts listed above.

In Figure 3 the effect of the nature of acids on change of the meaning of silica modulus is shown, also iron oxide content in the catalyst at the two-stage modification of natural zeolite is shown.

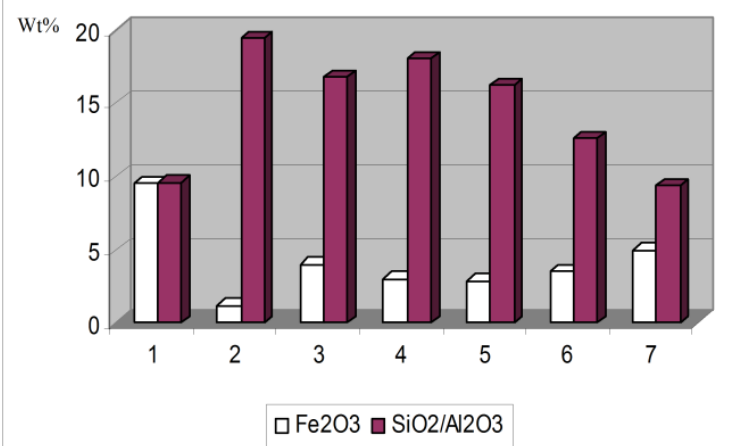

Fig. 3. The content of $\mathrm{SiO}_{2} / \mathrm{Al}_{2} \mathrm{O}_{3}$ and $\mathrm{Fe}_{2} \mathrm{O}_{3}$ in the samples: 1 - Kl; 2 - HKl-1/HSal-1 (1.75N HCl-10\% HSal); 3 - HKl1/HSal-2 (1.75N HCl-20\% HSal); 4 - HKl-1/HSal-2 (1.5N $\mathrm{HCl}-10 \% \mathrm{HSal}), 98^{\circ} \mathrm{C}$; 5- HKl-1/HSal-3 (1.0N HCl-10\% HSal), $98^{\circ} \mathrm{C} 6-\mathrm{HKl}-1 / \mathrm{H} 4 \mathrm{EDTA}$ (Soxhlet apparatus); 7 HKl-1/ $\mathrm{Na}_{2} \mathrm{H}_{2}$ EDTA.

The crystallinity of the catalysts prepared by the twostage process, first the inorganic and the organic acids were studied by X-ray and IR methods.

The IR spectra of the modified samples of natural zeolite first by inorganic $\mathrm{HCl}$, then by organic acids HSal or $\mathrm{H}_{4}$ EDTA fully preserved absorption bands which are characteristic of the crystal structure of clinoptilolite. IR spectra of the sample of clinoptilolite for example, treated first solution $1.75 \mathrm{~N} \mathrm{HCl}$, then a solution of $10 \%$ HSal characterized by absorption bands at $465,581,791,1067-1085,1636 \mathrm{~cm}^{-1}$ (see Figure 2, spectrum 3).

In X-ray diffraction patterns of zeolite - HKl-1/HSal1, HKl-1/HSal-2 and HK1-1/H4EDTA observed a slight decrease in intensity of the reflection $8.92 \AA$ and some decrease in sharpness of reflexes: $7.92 ; 6.65 ; 5.12 ; 3.98$; $3.55 ; 2.97 ; 2.73 \AA$ Á. Other responses, $7.92 ; 6.65 ; 5.12$; $3.98 ; 3.55 ; 2.97 ; 2,73 \AA$, which are typical for clinoptilolite does not show noticeable changes when modification by two-step method.

Thus, for use as catalysts in petrochemical processes, by modifying first inorganic acid step, then the organic acid step decationized and dealuminated varying degrees Shankanay clinoptilolit samples created. It was found that samples prepared on the basis of zeolite previously decationized by $1.75 \mathrm{~N}$ hydrochloric acid with followed by treatment with $10 \%$ aqueous solution of sulfosalicylic acid (HSal) are characterized by the lowest content of iron oxide and the absence of destruction of the crystal structure of clinoptilolite.

\subsection{Stepped modification of natural zeolite first with mineral and then with heteropolyacids}

IR spectra (Fig.4) of the original and $\mathrm{PW}_{12}-\mathrm{HPA}$ (or $\mathrm{PMo}_{12}$-HPA) presented the following main absorption bands: 510, 594, 789, 867, 962, 1065, 1400, 1618, 2850, $2925,3210,3419 \mathrm{~cm}^{-1}$ which are characteristic for the connection of $\mathrm{H}_{3} \mathrm{PW}_{12} \mathrm{O}_{40} \bullet 6 \mathrm{H}_{2} \mathrm{O}$ (or $\mathrm{H}_{3} \mathrm{PMo}_{12} \mathrm{O}_{40} \cdot 6 \mathrm{H}_{2} \mathrm{O}$ ).

Comparative analysis of the IR spectroscopy the samples HKl-1, PW 12 -HPA and PW $_{12}$-HPA/HKl-1 show that in these spectra characteristic absorption bands of clinoptilolite type zeolite are present: 465, 615, 780, $1060,1635,3460 \mathrm{~cm}^{-1}$. The IR spectra of the acid activated $\mathrm{K} 1$ sample these absorption bands appear very clearly, i.e. when decationization and dealumination natural zeolite retains its crystalline structure.

As it is seen in Figure 4, modification with HPA acid activated $\mathrm{Kl}$ sample uniquely revealed in the IR spectra of the obtained zeolite samples. For example, when one apply PW12-HPA in the zeolite, on the IR spectra of the zeolite samples shift of some absorption bands characteristic of the zeolites and the appearance of new bands observed. Thus, a shift of the band at $1060 \mathrm{~cm}^{-1}$ to $1097 \mathrm{~cm}^{-1}$ and $1108 \mathrm{~cm}^{-1}$. The absorption band of 780 $\mathrm{cm}^{-1}$ disappears, and at $800 \mathrm{~cm}^{-1}$ appears a new band, which is characteristic stretching vibration of Si-O-bond. Asymmetrical stretching vibrations at the end groups in the Si-O framework of clinoptilolite as indicated by the appearance and growth shoulder intensity at $1210 \mathrm{~cm}^{-1}$ in IR spectra. Given these changes can be concluded that in the zeolite structure Al-O-Si- linkages are broken and form Si-O-Si- linkages, aluminum enters the ion exchange position.

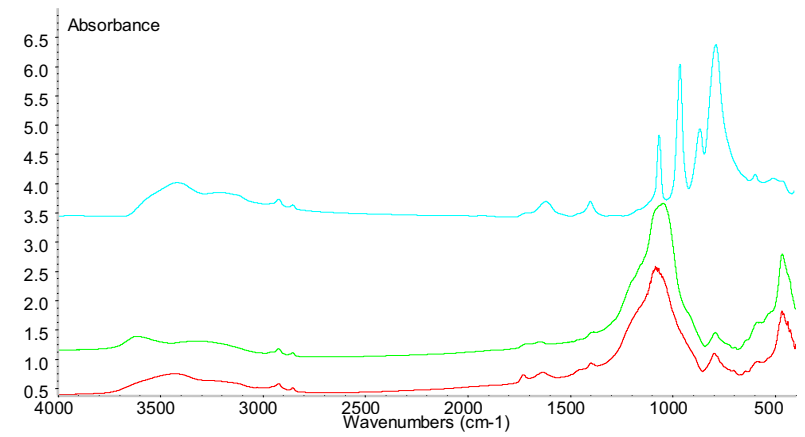

Fig. 4. IR spectra of samples $10 \% \mathrm{PW}_{12}-\mathrm{HPA} / \mathrm{HKl}-1$ and its components, where: a) IR spectra of the initial tungsten heteropolyacid- PW12-HPA $\left(\mathrm{H}_{3} \mathrm{PW}_{12} \mathrm{O}_{40} \cdot 6 \mathrm{H}_{2} \mathrm{O}\right)$, b) IR spectra of the HKl-1 sample, c) IR-spectra of sample $10 \% \mathrm{PW}_{12}-\mathrm{HPA}$ /HKl-1

X-ray of the samples also show a change in the structure of natural zeolite in the modification with HPA.

Thus, clearly revealed a decrease in the intensity of one of the main and the disappearance of some characteristic of the mineral clinoptilolite reflections in the diffraction patterns of samples $10 \% \quad \mathrm{PMo}_{12}-$ $\mathrm{HPA} / \mathrm{HK} 1-1$ and $10 \% \mathrm{PW}_{12}-\mathrm{HPA} / \mathrm{HK} 1-1$, which is apparently due to the partial amorphization of structures and changes in the composition of cationic surface of the zeolite.

These facts indicate the formation of a strong bond with the zeolite and HPA. It is believed that the substrate 
and the result achieved by calcination of catalyst $\mathrm{PW}_{12^{-}}$ HPA translation in highly dispersed condition in which the particles appear catalyst $\mathrm{PW}_{12}$-HPA specific adsorption and catalytic properties.

\section{Conclusion}

It can be concluded from the results that the modification of the sample of natural zeolite with various acids leads to changes in the composition and structure of clinoptilolite. Degrees of decationization and dealumination of clinoptilolite determined by the nature of the activating acid and bond strength of the cations in the mineral structure, which should be exchanged with hydrogen ions.

Indeed, all of the above factors have contributed to an increase in the catalytic activity of the cracking of paraffins $[13,14]$. In addition, an analysis of published data shows that ammonium salts of phosphorousmolibdenum heteropolyacid under certain conditions, can be used for the extraction of liquid radioactive waste of the lanthanides (Ce) and actinides (Am , Np) [16-19] . High selectivity of HPA salts with respect to radionuclides and high stability of natural ionizing radiation to the ion exchangers allowed using them effectively for the extraction of cesium from sea water, contaminated as a result of the accident at the Fukushima-I [16, 17].

The established relationship between the formations of catalytic systems based on the modification of natural zeolites and their catalytic activity offer great opportunities for targeted search for preparation of highly diverse hydrocarbon conversion catalysts.

\section{References}

1. Y.I. Isakov, H.M. Minachev Petrochemicals 3, 291 (1990)

2. J.A.Gonzalez, N. Travieso, A. Rkoya, J.L. Seoane, Kinetics and Catalysis 32(4), 907 (1991)

3. J. Rabo, Zeolites Chemistry and Catalysis over zeolites (Mir, Moscow, 1980)

4. Ch. Junwu, Acta petrol. sin. Petrol. Process. Sec. 20(5), 1 (2004)

5. K.A. Mehdiyev, J. Chem. Problems. 2, 324 (2007)

6. Z. Yuanzheng, Petrochem. Technol. 37(8), 852 (2008)

7. I.V. Kozhevnikov, Phys. Chem. 56(9), 1417 (1987)

8. T. Okuhara, Catalysts and Catalysis 45, 32 (2003)

9. Y. Wang, J. Wang Petrochem. Technol. 32, 453 (2003)

10. A.S. Kutergin, I.N. Kutergina Proc. of Ural State Technical University, 35(5), 126 (2004)

11. A. Kilincarslan, S. J. Akyil, Radioanal Nucl. Chem. 264(3), 541 (2005)

12. S. Akyil, M.J. Era,1 Radioanal. Nucl. Chem., 266(1), 89 (2005)

13. K.A. Kadirbekov Chem.journal of Kazakhstan 3, 103 (2010)
14. S.R. Konuspayev, K.A. Kadirbekov, A.T Sarsekova, D.R. Nurbaeva, D.K. Zhambakin, Pet. Chem. 50, 368 (2010)

15. K.A. Kadirbekov, Chem. J. of Kazakhstan 1, 188 (2010)

16. A. Iwanade, N. Kasai, H. Hoshina, J. Radional. Nucl. Ch. 293(2), 703 (2012)

17. Z. Huang, D. Zhang, Z. Tan, Adv. Mater. Res. 535, 2191 (2012)

18. A.P. Gupta, P.K. Varshney, Syn. React. Inorg. Met. 28(1), 105 (1998)

19. A.P. Gupta, S. Ikram, H. Agarwal, J. Indian. Chem. Soc. 80, 57 (2003) 